\title{
Clinical Trials on Stem Cells as a Therapeutic Agent: An Analysis From Clinical Trials Registry-India (CTRI)
}

Suman Ray ( $\sim$ sumanitrc@gmail.com )

NISTADS: National Institute of Science Technology and Development Studies CSIR https://orcid.org/0000-0002-9293-7591

Chandrasekhar Chavan

NISTADS: National Institute of Science Technology and Development Studies CSIR

\section{Research Article}

Keywords: Clinical trials, stem cells, therapeutic agent, stem cell therapy, randomised clinical trials, interventional

Posted Date: August 23rd, 2021

DOI: https://doi.org/10.21203/rs.3.rs-810776/v1

License: (a) (i) This work is licensed under a Creative Commons Attribution 4.0 International License. Read Full License 


\section{Abstract}

The stem cells have abundant potential for innovative therapeutic programs to replace or regenerate cells or tissues having functional impairment. Since the introduction of stem cell therapy using embryonic stem cells in 1998, the clinical use of the stem cells has increased. On the scientific ground, it is necessary to pass the clinical trials, otherwise, it may be recognised as an unproven therapy. The market of unproven stem cell therapy got attention when stem cell clinics started to advertise and claim to cure untreatable diseases. Indian Government has thus considered stem cell as a drug, and stem cells gone under clinical trials for market approval. In this study, we studied research trends related to clinical trials using stem cells as a therapeutic agent based on data obtained from the Clinical Trial Registry of India (CTRI). Our study showed that many clinical trials on the stem cells have been registered in the CTRI database, but only few of the clinical trials has been focusing on the actual stem cell drug development process. The greatest part of these trials were interventional and focused on bone marrow stem cells. On the other hand, only $2 \%$ of clinical trials actually focused on iPSCs. There is need to promote randomized clinical trials than single arm trials then our reliability on outcome from clinical trials may increases.

\section{Introduction}

Stem cells are the basic raw materials which has the potential to produce all other specially functionalized cell type or lineage. They have high capacity of self-replication and maintain itself as a niche. Stem cell therapy shows many promises as a treatment for previously untreatable and high-burden diseases. Ongoing research and clinical trials for the in treatments of spinal cord injury, heart failure, retinal and macular degeneration, and diabetes type 1 have proven that injecting stem cells at the target may help in reverting back to normal functioning (Menasche et al. 2015, Schwartz et al. 2015, Ilic and Ogilvie, 2017). The first criterion to denote an 'unproven therapy' is the lack of scientific rationale to suggest potential efficacy. According to Paul Knoepfler (Leask 2019), "There's little evidence that adipose, bone marrow and amniotic stem cells can be used safely and effectively for a diverse array of conditions marketed by for-profit clinics". While some studies have manifested that stem cell-based treatments can be safe but there is little clinical evidence at large that shows they are effective in human. (lijima $\mathrm{H}$ et al. 2018).

The expectations are high from the stem cell therapy but the scientific community argues about "unproven" stem cell therapy. The Indian government has taken it seriously on behalf of the Indian people due to continuous growth of "unproven" stem cell therapy which is considered as a drug in India. Therefore, it must comply with rigorous clinical trials procedure. India recently updated its guidelines on stem cell research (SCR), the National Guidelines for Stem Cell Research 2017. The approach of a "drug" firstly introduced in National Guidelines of Stem Cell Research 2013, and it is now a "rule" mentioned in the "New Drugs and Clinical Trials Rule, 2019.

Clinical Trials Registry-India (CTRI) is the clinical trial registration database of India that provides information on the implementation status of clinical trials from all over India. Although CTRI.nic.in does 
not provide comprehensive results of clinical trials, it is a database of the plans for individual trials and provides information about target diseases, sponsors/principal investigators, planned schedule and protocols of the clinical trials and enrollment of the subjects. Furthermore, since the database provides comprehensive information on the details of the content of the planned clinical trial, one can perform various targeted analyses by extracting and tagging attribute data from each clinical study plan (Pillamarapu M, et al., 2019).

Manifold studies aiming on the trends in stem cell research and therapy have been conducted so far but using either ClinicalTrials.gov or multiple databases (Fung et al 2017, Negoro et al 2018, Deinsberger et al 2020). A study on the clinical trials on stem cells using CTRI database is not reported yet. However, few studies mentioned about CTRI database and clinical trials on stem cells without any kind of analysis (Chaturvedi 2017, Pillamarapu M, et al., 2019).

The analysis of the current scenario of clinical trials on stem cells as a therapeutic agent would offer a broad overview on the clinical trials registered and their ongoing status in India. The present study is focused on the systematic search using the Clinical Trials Registry of India (CTRI) database. As part of this comprehensive analysis in particular, our study focuses on types of clinical trials, Types of study design, Recruitment status of clinical trials, Stem cell sources, Targeted diseases etc.

\section{Methods}

\section{a. Systemic search of database}

The objective of the study was to perform a complete analysis of all Indian clinical trials involving stem cells as a therapeutic agent. Firstly, a search was done in the database of "CTRI" using the search keywords "stem cells" OR "stem cell". This primary search was performed on 30 March 2021. The search algorithm is summarized in Supplementary figure XX. In total 135 studies were identified at "CTRI". Among them, 66 clinical studies had to be excluded because 68 of them did not involve stem cells as a therapeutic agent or the use of stem cells was optional. In total 66 clinical trials on the stem cells were identified and thoroughly analyzed using Microsoft Excel (Microsoft Inc., USA). The following properties of the 67 clinical studies have been used for content analysis: Registration number (CTRI number), Study title (Both Public and Scientific title of the study), Registration year, Recruitment status, Study type (Observational or Interventional), Phase of trial, Target disease, Type of stem cell used, Primary sponsor, Study duration, and Sample size (Number of participants).

\section{b. Content analysis of clinical trials}

The clinical studies were normally classified as observational or interventional study types. This classification based on the definition provided by the "ClinicalTrials.gov". So, we did not change the interpretation was provided by the CTRI. We, additionally include all those studies where the data is 'not provided' or 'not available' as a separate category for the analysis. All data are presented in percentage 
(and absolute numbers). Algorithm used for systematic CTRI database search on the clinical trials involving stem cells as a therapeutic agent is represented in Fig. 1.

\section{Results}

\section{a. Systematic search algorithm}

One hundred thirty-five clinical studies were identified using the predefined criteria in the database search using "CTRI". Out of those 69 studies had to be excluded, because they did not use stem cells as a therapeutic agent.

\section{b. Types of Clinical Trials}

Figure 1 shows types of clinical trials, all clinical trials were classified according to the types of clinical trials, it may either interventional or observational. The clear majority of interventional (70\%) clinical trials of stem cells were seen. Only $6 \%$ of trials were observational. The third category include $24 \%$ clinical trials, the data of these trials was not mentioned or not available in the CTRI database.

\section{c. Types of Study Design}

Figure 2 shows the types of study design for clinical trials involving stem cells. The major portion of clinical trials $43 \%$ were occupied by the Single arm design. Randomised clinical trials were $33 \%$ only whereas Non-randomised clinical trials $12 \%$. A significant contribution of other types of clinical study design (12\%) were observed.

\section{d. Phases of Clinical Trials}

Figure 3 indicates shows the distribution of clinical trials involving stem cells in Phases. Phase $1(42 \%)$ has been dominant in nature. Phase $2(23 \%)$ is situated at the second level. Phase 3 and Phase 4 respectively at $9 \%$ and $2 \%$ of trials having been recorded. Record of $24 \%$ clinical trials was not available in the database of CTRI.

\section{e. Recruitment Status}

Figure 4 shows the patient recruitment status of clinical trials involving stem cells. In the majority, $26 \%$ of clinical trials were not recruited yet after registration. Clinical trials were open for recruitment $(17 \%)$ slightly higher than completed recruitment (14\%). Clinical trials were shown in close to recruitment (7\%) and terminated trials (9\%). Record of $27 \%$ clinical trials was not available in the database of CTRI.

\section{f. Stem Cell Origin and Cell Source used in Clinical Trials}

In the Figs. 5 and 6 , the origin (autologous or allogenic) of each source and cell source in clinical trials was analyzed, respectively. Autologous stem cells (55\%) used more than the allogenic stem cells (45\%) in the clinical trials associated with stem cells. The contribution of the bone marrow derived stem cells $(74 \%)$ is too much higher than any other kind of stem cell source. Hematopoietic stem cells (9\%) and 
umbilical cord blood stem cells (8\%) were found at second and third position. The iPSC cells contributed only $2 \%$ in the overall clinical trials.

\section{g. Target Diseases of Clinical Trials involving stem cells}

Figure 7 shows the target diseases of clinical trials involving stem cell. The majority of clinical trials (27\%) were musculoskeletal disorders.

\section{h. Trend of Clinical Trials Registration involving stem cells}

Figure 8, shows trend of clinical trials registration involving stem cells extracted from CTRI database. The duration between 2008 and 2021 shows, all kind of trials were registered including prospectively and retrospectively registered. From 2008, the trials were registered at increasing order. In 2010 it reached to 15 trials were registered, which is highest number among the duration. Exceptional year was 2016 because no any trial was registered on this year. After 2012, the growth of registered trial were increasingly found with exception of 2016.

\section{Discussion}

In this study, we analyzed current scenario of clinical trials on stem cell as a therapeutic agent in India using the CTRI database. Worldwide, the stem cell treatment considered as a cell-based therapy or simply "stem cell therapy" but in India, it considered as a "drug". Therefore, the notion of treatment has changed from "therapy" to "drug". After considering as a drug, the regulatory requirement has also been changed (Qiu et al, 2020).

Using the database of clinical trials several studies have been published on the stem cell therapy using different perspectives. All these studies were conducted using ClinicalTrials.gov and also gathering the data from other international databases (Monsarrat et al, 2016, Fung et al, 2017, Negoro et al 2018, Negoro et al 2019, Deinsberger et al, 2020). Although these studies showed clinical trials conducted in India but scenario of Indian context was limited. Another most important thing is that these all studies used prime source was ClinicalTrials.gov not CTRI database. Our study is solely dependent on the CTRI database with the acceptance of some limitations of this database. Pillamarapu et al, 2019 have described these limitations and many information is not seen or missing on the CTRI database. Similar situation is also found in a study done by Negoro et al, 2018 using ClinicalTrials.gov.

Our study is based on the clinical trials on stem cells registered in CTRI database, the priority being given to interventional types (70\%) of trials (Fig. 1). The single armed trials (43\%) were mostly used for conducting a trial instead of randomised clinical trials (RCTs) (33\%) (Fig. 2). The RCTs have important value in the field of clinical trial field. The study showed Phase 1 clinical trials (43\%) and Phase 3, only $9 \%$ of the total trials. When focusing on the recruitment status of clinical trials, we found that, majority of clinical trials were in the open to recruitment status (26\%). The patient recruitment was completed in only $14 \%$ of the trials. The autologous stem cell sources (55\%) were slightly higher than the allogenic stem cell sources utilised. That is, the autologous stem cells is more preferred than the allogenic stem cells used 
during the stem cell therapy (Fig. 5). Among the scrutinised data, we found that, bone marrow was the most favoured stem cell source in this field (Fig. 6).

The Stempeucel $\AA^{\circledR}$ is a product have market authorisation approval. The Stempeutics have gotten the market authorization for Critical Limb Ischemia due to Buerger's Disease and Critical Limb Ischemia due to Peripheral Arterial Disease from the CDSCO (Stempeutics, 2021). The Stempeucel ${ }^{\circledR}$ is currently under clinical trials for Knee Arthritis, which is now in the Phase 3 (CTRI/2018/09/015785). This drug also applying for the Diabetic Foot Ulcer, which is also in the Phase 3 (CTRI/2019/12/022351). In woman, Asherman syndrome is a rare disease of uterus. AllMS New Delhi have conducted pilot level clinical trials on this disease, which is now in Phase 4 (CTRI/2013/08/003896). This single arm trial was registered in 2013 and open for recruitment. The future of iPSCs is not clear from this analysis because it has only one registered clinical trial (CTRI/2019/11/022000). This trial is observational type and RCTs not done yet. The hype from iPSC is increased and promoted by the Nobel Prize in 2012. India is far behind in the race for creating and implementing iPSC technology (Lu and Zhao 2013, Deinsberger et al. 2020).

The time required for the product development cannot be concluded from our stduy because of data insufficiency on the CTRI database. Therefore, it is necessary to trace the clinical development of stem cell based therapeutic products from another information sources. The aim of this paper is to show a comprehensive analysis of clinical trials involving stem cell as a therapeutic product in India. Many businesses market "unproven treatments make positive but imprecise and unquantified claims about the therapeutic promise of the stem cell interventions they promote," explained by Leigh Turner Associate Professor at University of Minnesota Center for Bioethics, School of Public Health and College of Pharmacy (Turner, 2018). Working with stem cell, it arises many ethical, societal, political, and legal issues. Hence each country has attempted to regulate clinical translation of stem cell for the public (Turner, 2018; Berger et al, 2016).

The Indian Government released the National Health Policy 2017. This policy guideline showed very ambitious goals but fail to provide any details of regenerative medicine or stem cell therapy. Therefore, it indirectly affects the all activities related to stem cell based drug development process. Department of Biotechnology have recently released second strategy statement on the development of biotechnology in India i.e. National Biotechnology Development Strategy 2021-2025. It ensure about helping development of future medicine including regenerative medicine or stem cell therapy. The draft on the Science, Technology, and Innovation Policy 2020 has been released by Department of Science and Technology. This draft shows promise for development and promotion of future medicine. The Indian government aims to promote the stem cell research and therapy through clinical trials then in future, India will be a real and an affordable destination for the "stem cell tourism".

\section{Conclusions}

Our study shows that many clinical trials on the stem cells have been registered in the CTRI database, but only few these clinical trials is been focussing on the actual stem cell drug development process. The 
greatest part of these interventional trials is focusing on the use of bone marrow stem cells and only $2 \%$ of clinical trials on iPSCs. Hence, more attention on the iPSCs is needed for the future use. There is need to promote randomised clinical trials than single arm trials so that reliability on outcome from clinical trials may be enhanced.

\section{Declarations}

\section{Ethical Approval}

The manuscript is based on systematic review analysis, does not require any ethical approval.

\section{-Consent to Participate}

The manuscript is based on systematic review analysis, does not involve any participation of indiduals or a clinical study.

\section{-Consent to Publish}

The manuscript is based on systematic review analysis, does not require any ethical approval.

\section{-Authors Contributions}

Suman Ray provided the concept of the study and preparation of the manuscript. Chandrashekhar did the systematic review analysis and involved in the preparation of the manuscript.

\section{-Funding}

No funding support.

\section{-Competing Interests}

The Authors have no competing or conflict of interest.

\section{-Availability of data and materials}

The data is given in the manuscript and if any furthaher clarification required, the dtata will be made available by contacting the authors individually.

\section{Acknowledgements}

Authors would like to sincerely thank Director, NIScPR (New Delhi) for providing constant support in completing the research work undertaken. The author also sincerely thanks to Council of Scientific and Industrial Research for providing financial assistance as Senior Research Fellowship (CSIR-SRF) to Chandrashekhar Chavan for conducting this study.

\section{References}

1. Berger, I., Ahmad, A., Bansal, A., Kapoor, T., Sipp, D., John, E. J., \& Rasko 'Global Distribution of Businesses Marketing Stem Cell-Based Interventions'. Cell Stem Cell 19, no. 2(August 2016). : 158- 
62. https://doi.org/10.1016/j.stem.2016.07.015.

2. Chaturvedi, M., Gogtay, N. J., \& Thatte, U. M. (2017). 'Do Clinical Trials Conducted in India Match Its Healthcare Needs? An Audit of the Clinical Trials Registry of India'. Perspectives in Clinical Research, 8(no. 4), 172. https://doi.org/10.4103/2229-3485.215970.

3. Clinical Trials Registry of India, ICMR- National Institute of Medical Statistics http://ctri.nic.in (accessed in March 2021)

4. Deinsberger, J., Reisinger, D., \& Weber, B. (December 2020). 'Global Trends in Clinical Trials Involving Pluripotent Stem Cells: A Systematic Multi-Database Analysis'. Npj Regenerative Medicine, 5(no. 1), 15. https://doi.org/10.1038/s41536-020-00100-4.

5. Department of Health and Family Welfare, Ministry of Health and Family Welfare https://cdsco.gov.in/opencms/export/sites/CDSCO_WEB/Pdfdocuments/NewDrugs_CTRules_2019.pdf\#page=147\&zoom=auto,-91,842

6. Fung, M., Yuan, Y., Atkins, H., Shi, Q., \& Bubela, T. 'Responsible Translation of Stem Cell Research: An Assessment of Clinical Trial Registration and Publications'. Stem Cell Reports 8, no. 5(May 2017). : 1190-1201. https://doi.org/10.1016/j.stemcr.2017.03.013.

7. Ilic, D., \& Ogilvie, C. (2017). Concise review: human embryonic stem cells-what have we done? What are we doing? Where are we going? Stem Cells, 35, 17-25

8. Indian Council of Medical Research \& Department of Biotechnology (ICMR-DBT).National Guidelines for Stem Cell Researchhttp://icmr.nic.in

9. Leask, F.. Mapping the stem cell ecosystem: an interview with Paul Knoepfler. RegMedNet. https://www.regmednet.com/users/3641-regmednet/posts/41639-mapping-the-stem-cell-ecosysteman-interview-with-paul-knoepfler (Accessed on 14 November 2019).

10. Lu, X., \& Zhao, T. (2013). 'Clinical Therapy Using IPSCs: Hopes and Challenges'. Genomics Proteomics Bioinformatics, 5 .

11. Menasche, P., Vanneaux, V., Hagege, A., Bel, A., Cholley, B., Cacciapuoti, I. ... Larghero, J. (2015). Human embryonic stem cell-derived cardiac progenitors for severe heart failure treatment: first clinical case report. Eur Heart J, 36, 2011-2017

12. Monsarrat, P., Vergnes, J. N., Ravaud, P., Kémoun, P., Sensebé, L., \& Casteilla, L. Valérie Planat-Bénard, , and. 'An Innovative, Comprehensive Mapping and Multiscale Analysis of Registered Trials for Stem Cell-Based Regenerative Medicine'. STEM CELLS Translational Medicine 5, no. 6(June 2016). : 82635. https://doi.org/10.5966/sctm.2015-0329.

13. Negoro, T., Takagaki, Y., Okura, H., \& Matsuyama, A. 'Trends in Clinical Trials for Articular Cartilage Repair by Cell Therapy'. Npj Regenerative Medicine 3, no. 1(December 2018). : 17. https://doi.org/10.1038/s41536-018-0055-2.

14. Pillamarapu, M., Mohan, A., \& Saberwal, G. (December 2019). Trials, 20, no. 1. 535. https://doi.org/10.1186/s13063-019-3592-0.'An Analysis of Deficiencies in the Data of Interventional Drug Trials Registered with Clinical Trials Registry - India' 
15. Qiu, T., Hanna, E., Dabbous, M., Borislav, B., \& Toumi, M. (2020). 'Regenerative Medicine Regulatory Policies: A Systematic Review and International Comparison'. Health Policy. https://doi.org/10.1016/j.healthpol.2020.05.004.

16. Schwartz, S. D., Regillo, C. D., Lam, B. L., Eliott, D., Rosenfeld, P. J., Gregori, N. Z. ... Lanza, R. (2015). Human embryonic stem cell-derived retinal pigment epithelium in patients with age-related macular degeneration and Stargardt's macular dystrophy: follow-up of two open-label phase $1 / 2$ studies. Lancet, 385, 509-516

17. Stempeutics Pvt. Ltd. https://www.stempeutics.com/stempeucel.html (Accessed on 2021, July 27).

18. Turner, L. (2018). 'The US Direct-to-Consumer Marketplace for Autologous Stem Cell Interventions'. Perspectives in Biology and Medicine, 61(no. 1), 7-24. https://doi.org/10.1353/pbm.2018.0024.

\section{Figures}

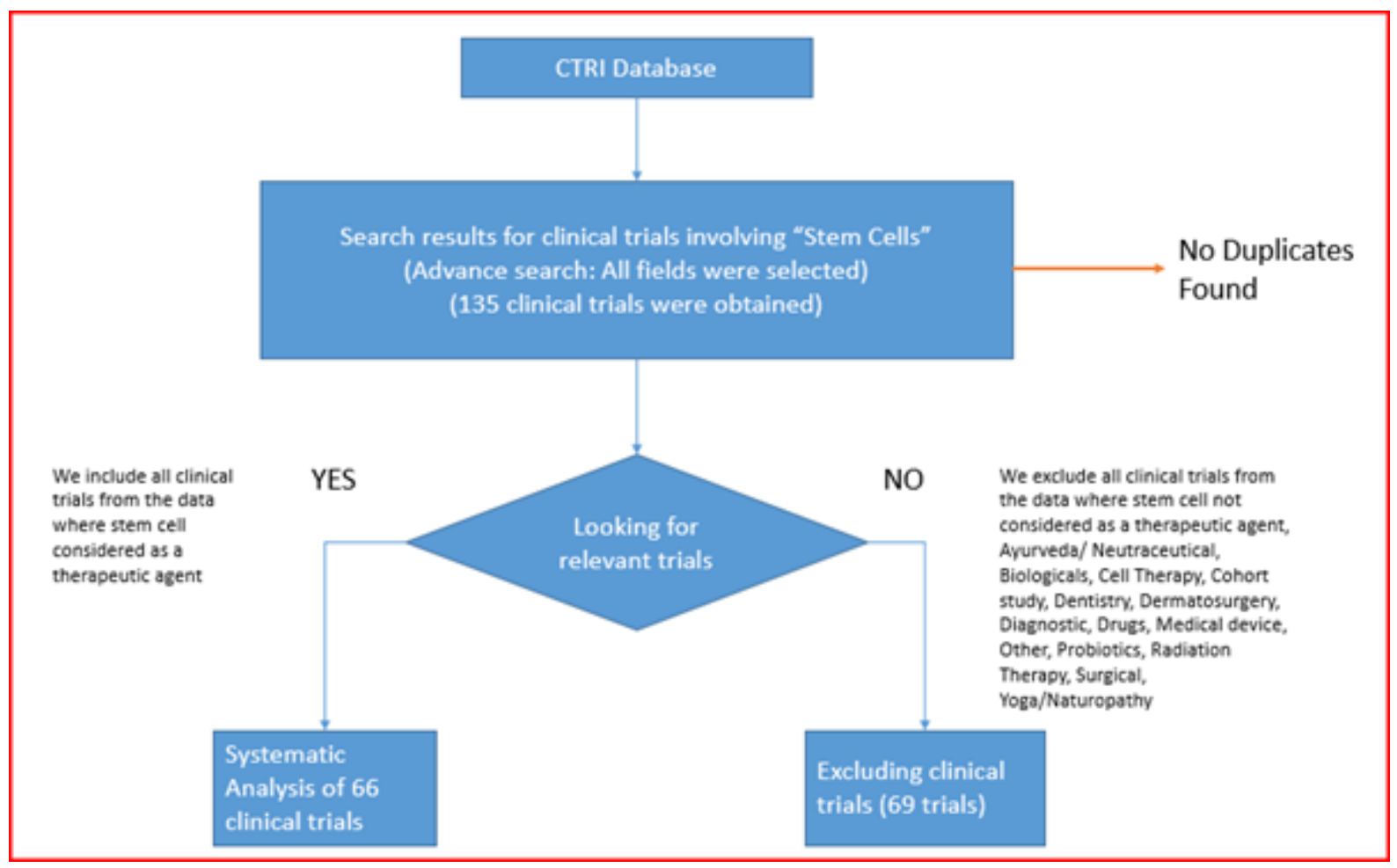

Figure 1

Flowchart for searching the clinical trials on stem cells as a therapeutic agent registered in the CTRI database. 


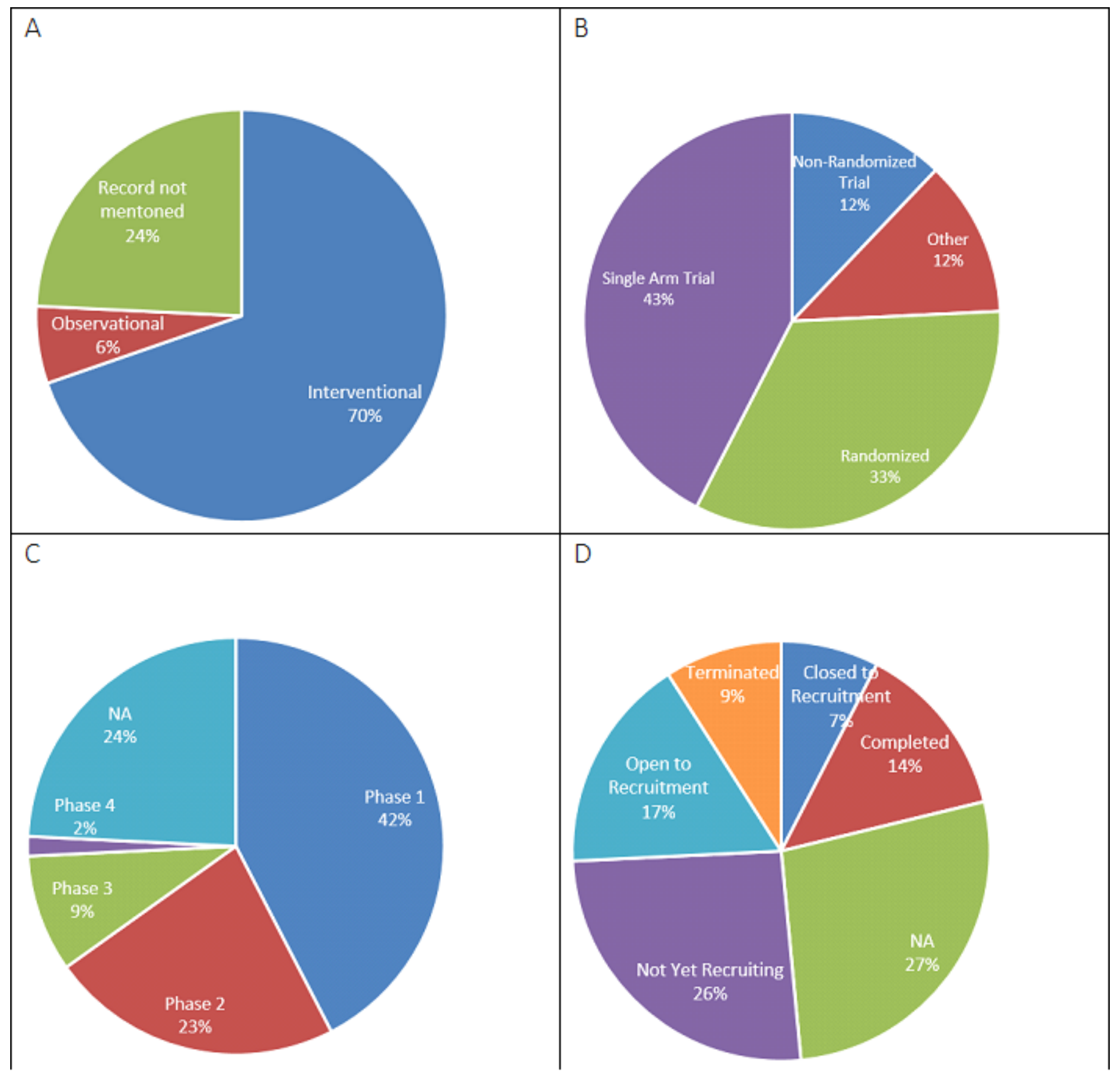

\section{Figure 2}

Analysis of the clinical trials on stem cells as a therapeutic agent registered in the CTRI database A) Percentage of the types of study B) Percentage of the types of study designs C) Percentage of the clinical trials Phases, and D) Percentage of the recruitment phases of the clinical trials. 


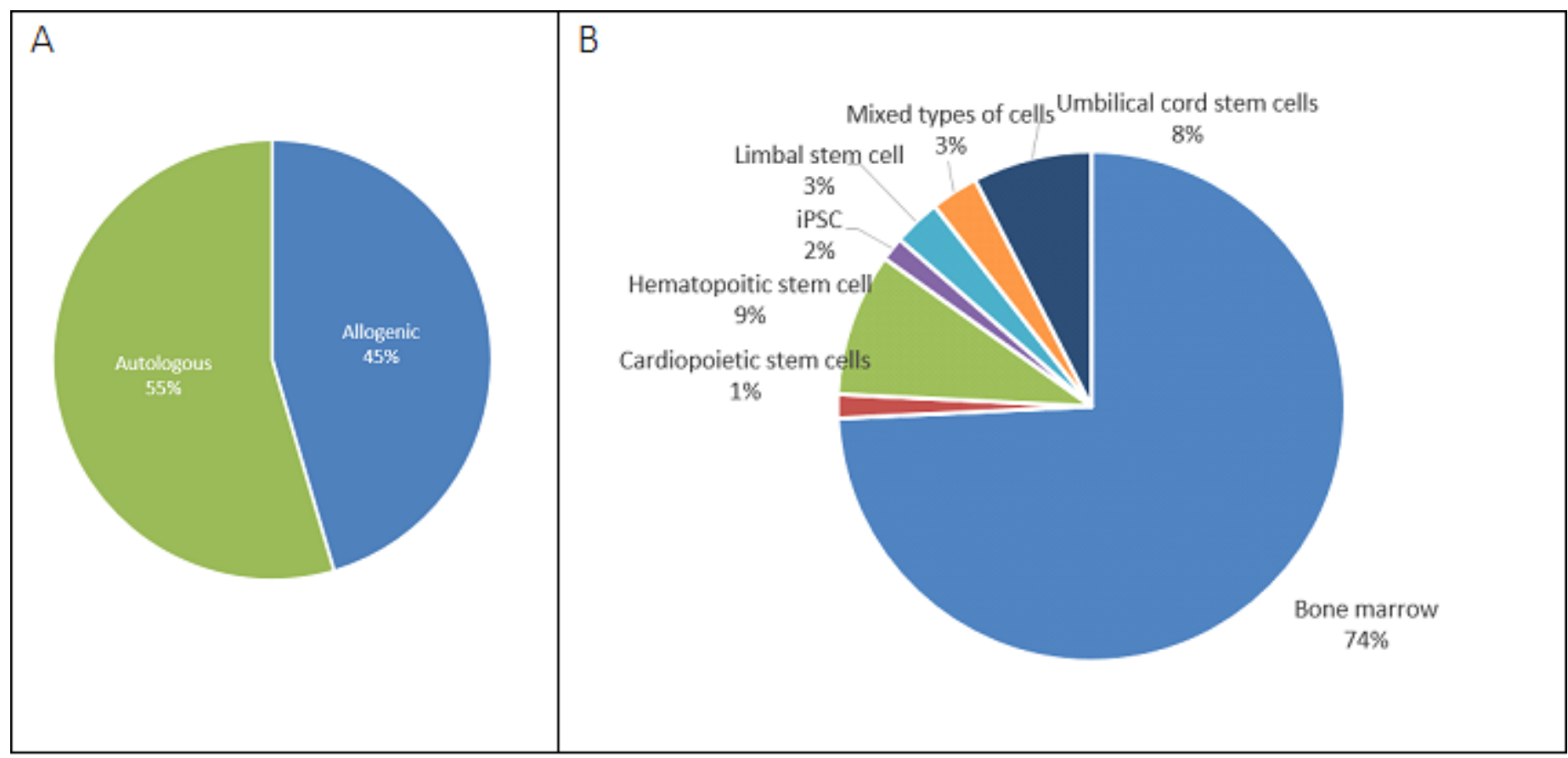

\section{Figure 3}

Analysis of the clinical trials on stem cells based on A) origin of the cells, and B) source of cells registered in the CTRI database (in percentage).

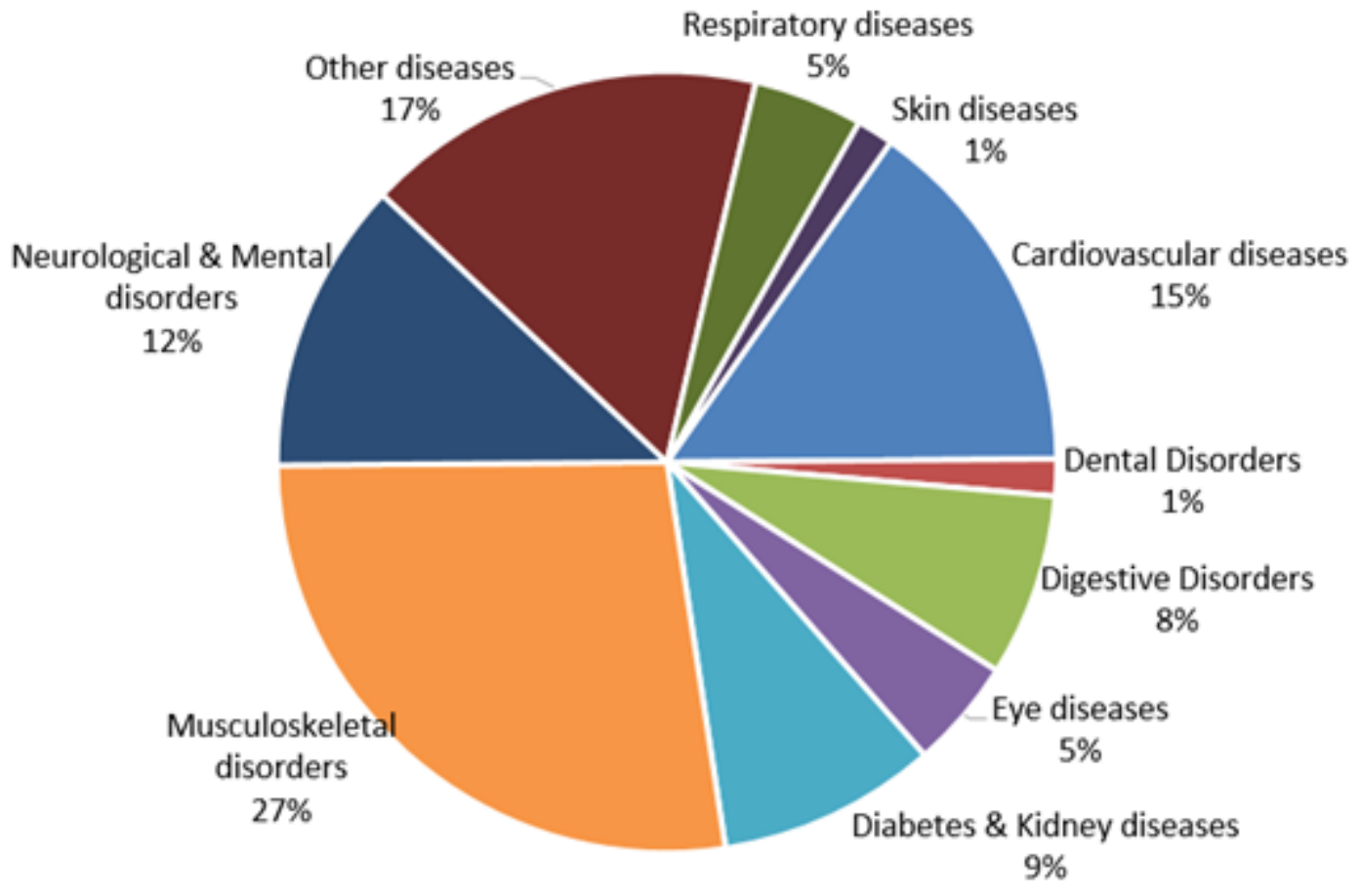

\section{Figure 4}

Analysis of the clinical trials on stem cells as a therapeutic agent registered in the CTRI database based on Disease category (in percentage). 


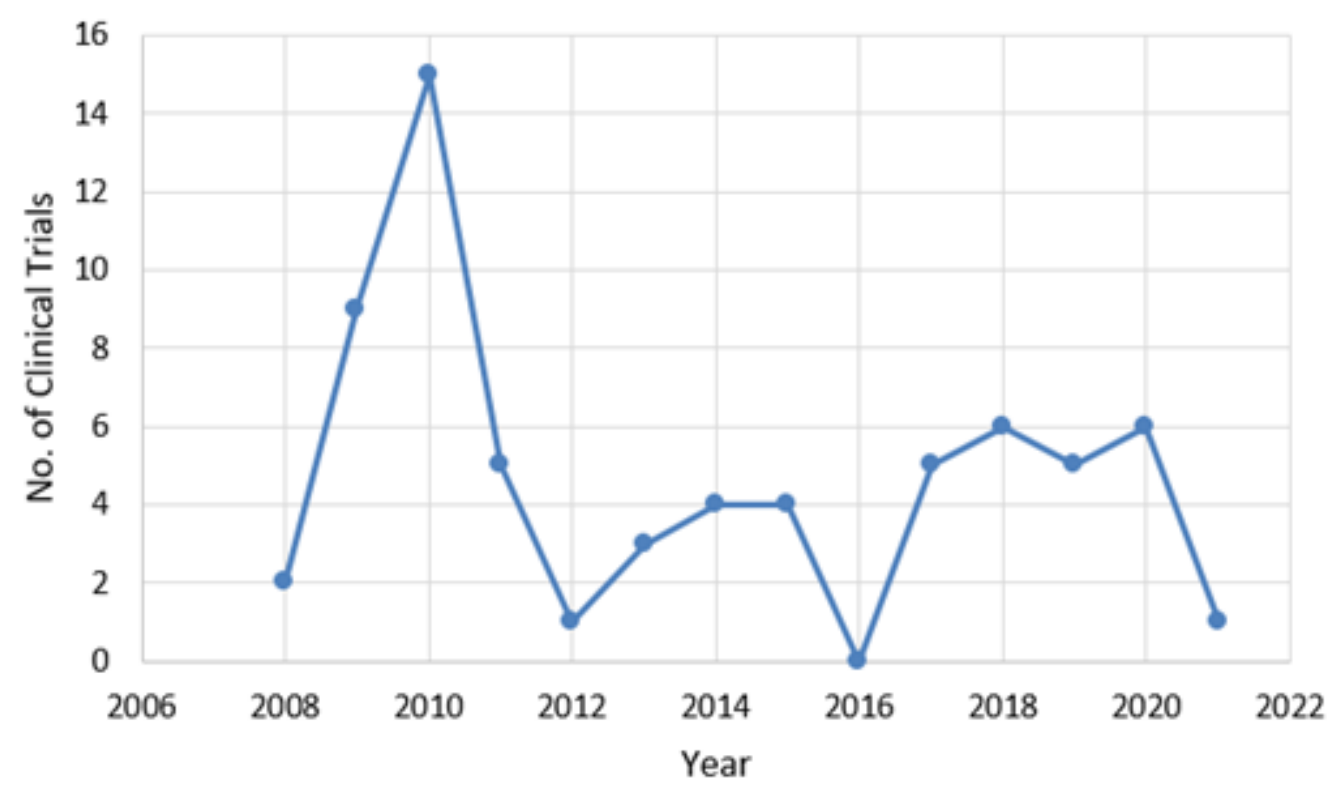

Figure 5

Trend of clinical trials on stem cells as a therapeutic agent registered on the CTRI database: The clinical trials registration from 2008 to March 2021. The trial registration includes both kind of trials includes prospectively and retrospectively.

\section{Supplementary Files}

This is a list of supplementary files associated with this preprint. Click to download.

- Graphicalabstract.docx 